\title{
An Unusual and Rare Case of Generalized Multiple Epidermoid Cysts with a Giant Epidermoid Cyst
}

This article was published in the following Dove Press journal: International Medical Case Reports Journal

\author{
Eva Krishna Sutedja (iD \\ Laila Tsaqilah \\ Endang Sutedja \\ Inne Arline Diana \\ Hendra Gunawan (D) \\ Department of Dermatology and \\ Venereology, Faculty of Medicine, \\ Universitas Padjadjaran - Hasan Sadikin \\ General Hospital, Bandung, Indonesia
}

Correspondence: Hendra Gunawan Department of Dermatology and Venereology, Faculty of Medicine, Universitas Padjadjaran - Hasan Sadikin General Hospital, Jl. Pasteur No. 38, Bandung, West Java 40161, Indonesia Tel/Fax +62 222032426 ext. 3449 Email h.gunawan2016@unpad.ac.id

\begin{abstract}
Epidermoid cyst (EC) is a cyst containing keratin and its breakdown products, that is surrounded by an epidermoid wall. EC can occur in both men and women, especially in youngand middle-aged adults. The clinical features of EC include asymptomatic, well-demarcated, and skin-colored to yellowish subcutaneous or dermal nodules with a punctum on the middle of the lesion which can occur anywhere on the body. This type of cyst is usually solitary with diameter up to $5 \mathrm{~cm}$, or rarely, there are multiple with diameters of more than $5 \mathrm{~cm}$, which is classified as a giant EC. Here, we report a case of generalized multiple ECs with a giant EC on the left gluteal region of a 19-year-old male with complaints of asymptomatic skin-colored nodules with central punctum on the right temple, chest, back, and gluteal regions for five years. Correlation between the clinical and histopathological findings in the form of cysts containing keratin and lined by wall composed of stratified squamous epithelia established the diagnosis of EC. The patient underwent surgical procedures for the skin-colored nodules on the chest, back, and gluteal regions. He also received triamcinolone acetonide intralesional injection for the skin-colored nodule on the right temple. After four months of follow-up, there was no recurrence, and all the skin-colored nodules were completely removed. EC should always be considered when diagnosing a skin-colored nodule even if the manifestations are generalized multiple and giant nodules, as in our case, demonstrating a rare and unusual case of EC, to the best of our knowledge.
\end{abstract}

Keywords: epidermoid cyst, generalized, giant, unusual

\section{Introduction}

Epidermoid cyst (EC), also known as keratin cyst, epidermal cyst, epidermal inclusion cyst, epithelial cyst, or infundibular cyst, is a cyst containing keratin and its breakdown products surrounded by an epidermoid wall composed of stratified squamous epithelia. $^{1-3}$ This cyst is commonly identified in young- and middle-aged adults, both men and women equally. ${ }^{1,3}$ An EC is classically an asymptomatic dermal or subcutaneous mobile nodule with central punctum ${ }^{1}$ and can be found anywhere, but is most commonly found on the face, neck, chest, upper back, scrotum, and genital area. It can also be found on the gluteal region, palms, and soles due to penetrating trauma. ${ }^{4}$ The lesion is well-demarcated, skin-colored to yellowish, ${ }^{2}$ and slow-growing. ${ }^{1}$ The diameter may vary from a few millimetres to several centimetres. ${ }^{2}$ A cyst with diameter more than $5 \mathrm{~cm}$ is called giant EC and it is a rare clinical occurrence. ${ }^{5,6}$ Multiple ECs are rarely found $^{7}$ and can be seen in patients with severe acne vulgaris. ${ }^{3}$ There are several case reports of giant EC on the gluteal region ${ }^{8,9}$ and several case reports of multiple ECs on hairy scalp. ${ }^{10,11}$ However, there was only one case report of multiple ECs which spread to 
several locations of the body. ${ }^{12}$ In this report, we present a case of generalized multiple ECs with a giant EC on the left gluteal region which is an unusual and rare manifestation of EC.

\section{Ethical Approval}

This study was conducted in compliance with the Declaration of Helsinki, Good Clinical Practices, local regulatory requirements, and was approved by the Medical Ethics Committee of Hasan Sadikin General Hospital Bandung (approval number: LB.02.01/X.6.5/220/2020).

\section{Consent for Publication}

The patient signed informed consent forms. He also signed forms giving consent for the use of case details and images for publication and for scientific purposes.

\section{Case Presentation}

A 19-year-old male patient presented with slow-growing asymptomatic skin-colored nodules with punctum on the right temple, chest, back, and gluteal regions for five years. He was not aware of the mass on the back and gluteal regions until he experienced a vague sensation originating from the back and gluteal regions when lying and sitting down. The lesions on the right temple and chest first appeared as skin-colored papules which slowly multiplied and increased in size. The patient had not sought treatment for the lesions. He has history of acne vulgaris since adolescence. There was no previous history of similar complaint in the patient nor his family. He did not experience pain or other complications of skin lesions, such as secondary infection, inflammation, and suppuration. There was no history of malignancy in the patient nor his family. He did not experience hidradenitis suppurativa, pilonidal sinus disease, or any syndrome. There was no history of consanguineous marriage in the mother's family nor his father's family.

Clinical examination of the lesions revealed painless skincolored nodules on the right temple, chest, back, and gluteal regions with a central black punctum (Figure 1). The size varied from $0.3 \times 0.2 \times 0.1 \mathrm{~cm}$ to $6 \times 5 \times 3 \mathrm{~cm}$. There was no definite distortion of the surface anatomy from visual examination nor a non-tender firm-to-hard mass fixed to the underlying structures on palpation. Comedones were identified on the face, chest, and back, whereas scars were identified on the face, lower back, and gluteal regions. Histopathological examination of the three skin-colored nodules on the back revealed cysts containing keratin lined by wall composed of stratified squamous epithelia and the nuclei of epithelial cells were within normal limit (Figure 2). This histopathological finding supported the diagnosis of EC. Therefore, the diagnosis of multiple ECs with a giant EC was established. However,
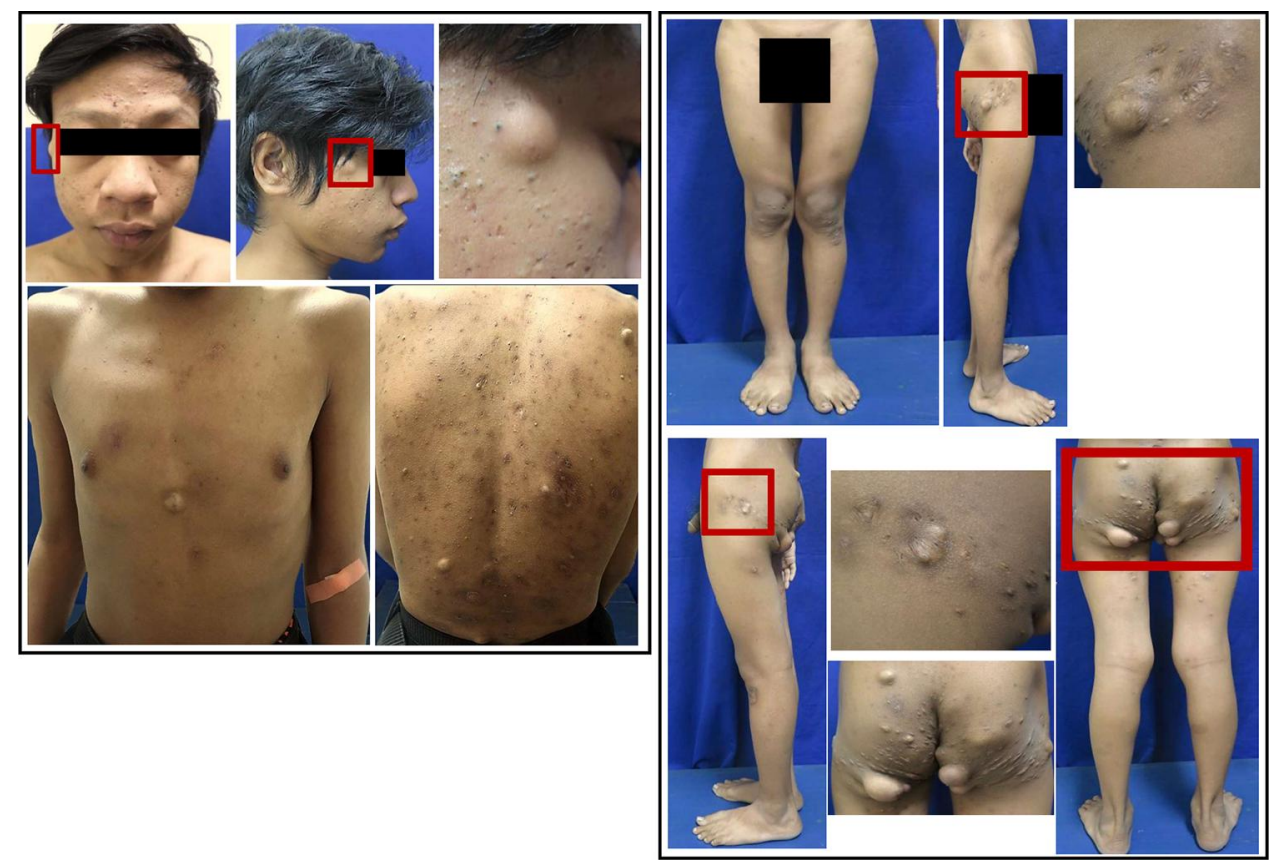

Figure I An unusual and rare clinical manifestation of EC. Generalized multiple ECs on the right temple, chest, and back with a giant EC on the left gluteal region presenting as skin-colored nodules.

Abbreviation: EC, epidermoid cyst. 


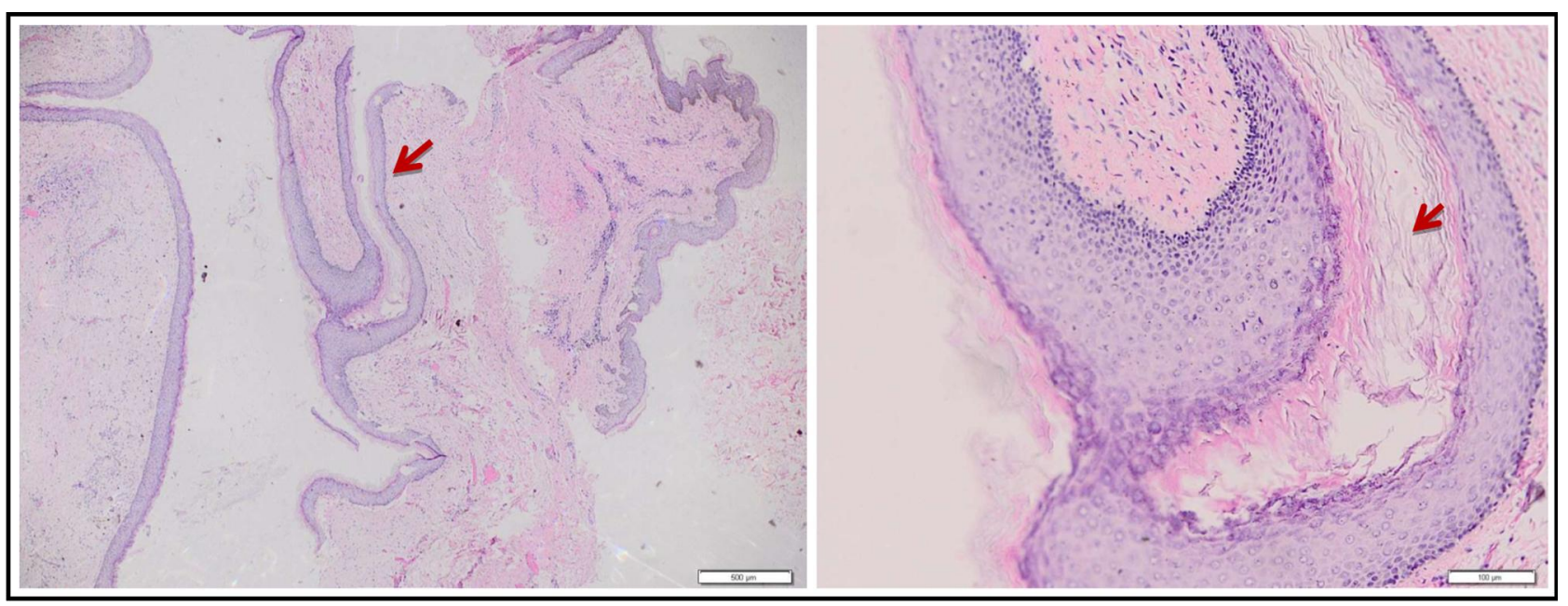

Figure 2 Histopathological findings (H\&E staining, 20x and 100x). A cyst containing keratin and lined by wall of stratified squamous epithelium (red arrows).

further investigation with genetic analysis to rule out possible genetic causes were not possible due to the unavailability of a genetic laboratory in our center.

Surgical excision was performed for the mass on the back (on the seventh day) (Figure 3A). Extirpation of cysts with conventional wide excision was performed for the mass on the upper left gluteal region (on the 48th day), chest (on the 55th day), and lower left gluteal region (on the 61st day)
(Figure 3B-D) to produce less scarring for optimal cosmetic results. He also received $0.2 \mathrm{~mL}$ of triamcinolone acetonide $10 \mathrm{mg} / \mathrm{mL}$ intralesional injection for the skin-colored nodule on the right temple (on the 58th day) to achieve optimal cosmetic results. Two weeks after the interventions, the wound healed well and there were no signs of infections. After four months of follow-up, there was no recurrence and all skin-colored nodules were completely removed.
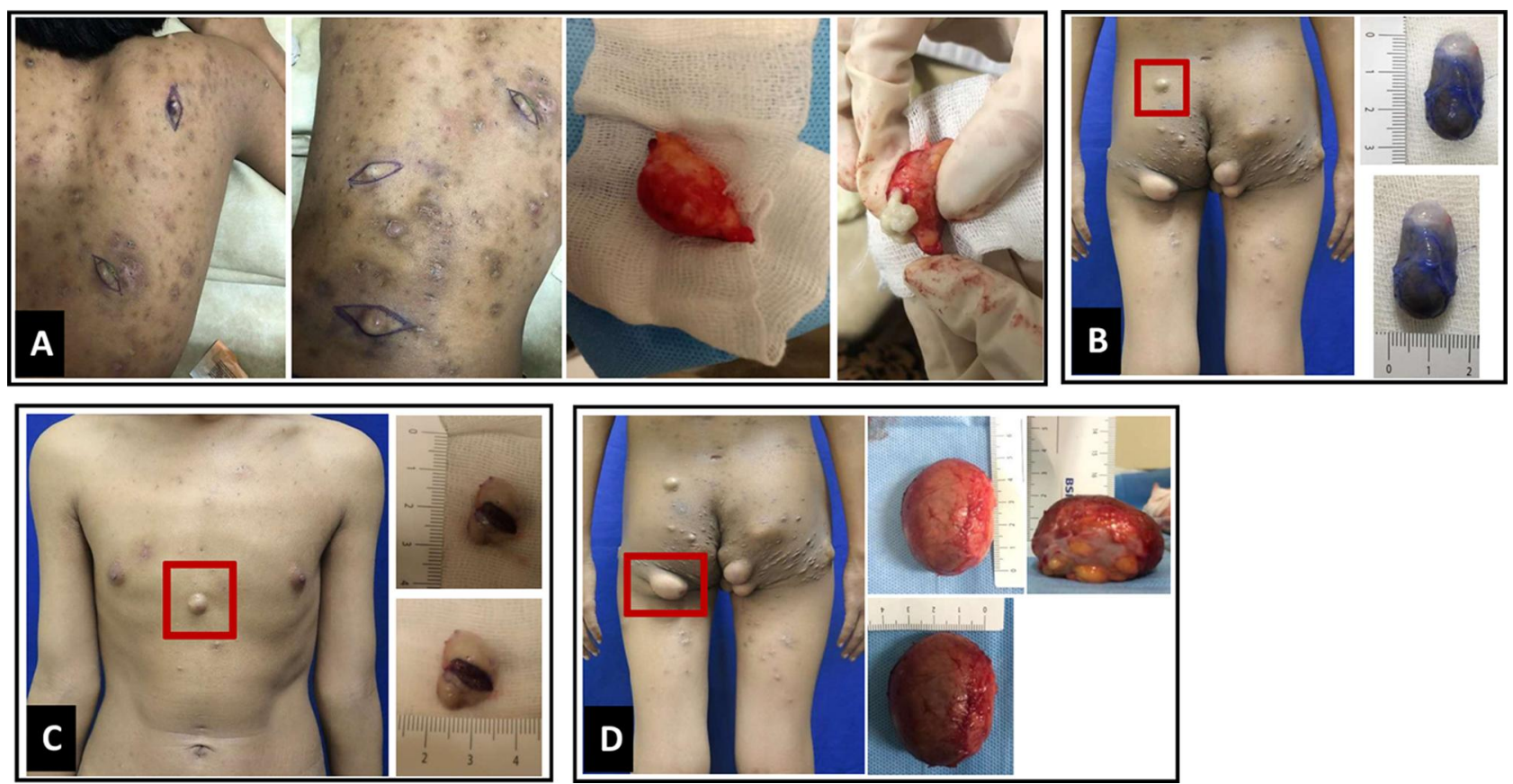

Figure 3 Medical intervention of EC. (A) Conventional wide excision technique for the ECs on the back. (B-D). Minimal excision technique for the ECs on the chest and gluteal regions.

Abbreviation: EC, epidermoid cyst. 


\section{Discussion}

Epidermoid cyst commonly results from plugged pilosebaceous units lined by a wall of epithelia resembling the infundibulum of hair follicle, and expresses the same cytokeratin profile. Thus, EC is thought to be derived from this structure. ${ }^{1}$ Punctum is a clinical characteristic of EC that can appear as a giant blackhead with black keratin plug, which indicates that the cyst is connected to the surface of the skin through a duct which is fully filled with keratin. This theory explains why EC is often found on the face, neck, chest, and back regions. ${ }^{13}$ This is similar to the pathogenesis of acne vulgaris. ${ }^{4}$ Multiple ECs originate from comedones $^{3,4}$ that can be seen in patients with acne vulgaris $^{2,3}$ or with significant history of acne vulgaris. ${ }^{2}$ Therefore, disruption of the hair follicle plays an important role in the pathogenesis of acne vulgaris. ${ }^{3,4}$ In acne vulgaris, there are sebaceous gland hyperplasia, increased sebum production, and increased rate of keratinocytes proliferation in the ducts and acro-infundibulum of sebaceous gland. Keratinocytes of the ducts and follicles in acne vulgaris are dense and coherent leading to a plaque which causes blockage of the follicles' infundibulum due to accumulation of keratin, sebum, and bacteria. The obstruction is marked by follicular dilation. ${ }^{14}$ There was a case report of multiple ECs on both cheeks of a 53-year-old man for 12 months which led to facial deformity. He had history of cystic acne during adolescence. ${ }^{15}$

An EC may also arise from traumatic implantation of epidermal cells into the deeper layer ie, dermis, ${ }^{1}$ called inclusion cysts. ${ }^{3}$ In the dermis, epidermal cells can proliferate and collect debris and keratin, leading to formation of the cysts. ${ }^{13}$ Trauma is the main cause in this theory, but it can go unnoticed and occur for several years before the lesion arises. ${ }^{8}$ This theory explains why EC can be found on the locations of the body prone to trauma, eg, back, gluteal, and extremities regions. ${ }^{13}$

In this report, multiple ECs on the right temple, chest, back, and gluteal regions could be caused by the keratin plugging the pilosebaceous unit which is similar to the pathogenesis of acne vulgaris. At first, the multiple ECs is thought to have originated from the comedones of acne vulgaris, while multiple ECs on the back and a giant EC on the gluteal region could be caused by implantation of epidermal cells into deeper tissue due to unnoticed trauma.

The diameter of ECs ranged from a few millimetres to $5 \mathrm{~cm}$. EC usually enlarges slowly, ${ }^{1}$ as the rate of growth is not more than $0.5 \mathrm{~cm}$ per year. ${ }^{5} \mathrm{~A}$ giant EC is defined as an
EC with diameter exceeding $5 \mathrm{~cm}^{1}$ and are commonly found on the gluteal region and scrotum. ${ }^{9}$ Due to the large size of the giant EC, the hair follicles above the cyst are stretched; hence, the punctum is often difficult to identify. ${ }^{5}$ EC is usually solitary and is rarely multiple. ${ }^{7}$ There were several case reports of solitary giant EC on the gluteal region $^{8,9,13}$ and several cases of multiple ECs on the scalp. ${ }^{10,11}$ However, there was just one case report of multiple EC on several locations. ${ }^{10}$ In this case report, the patient had a rare clinical manifestation of EC. He had a skincolored nodule with size of $6 \times 5 \times 3 \mathrm{~cm}$ on the left gluteal region and multiple ECs on several locations (Figure 1).

The definite diagnosis of EC is established based on clinical and histopathological findings. ${ }^{3}$ The histopathological features of EC are cysts containing keratinous mass, which are lined by stratified squamous epithelia showing epidermal keratinization, formation of keratohyalin granules, and flattened surface epithelium. As such, they are thought to be derived from or mimic the infundibular portion of the hair follicle. ${ }^{16}$ The result of histopathological examination of this patient revealed cysts coated by stratified squamous epithelia and containing keratinous mass which supported the diagnosis of EC (Figure 2).

Intervention for $\mathrm{EC}$ can be considered for cosmetic purposes or if there were recurrent history of inflammation, increasing size of the skin lesion which can interfere daily activities, ${ }^{17}$ and discomfort sensations. ${ }^{13}$ These interventions include non-surgical and surgical approaches. One nonsurgical approach is triamcinolone acetonide intralesional injection. ${ }^{18}$ The surgical techniques involve conventional wide excision, minimal excision, and punch excision. ${ }^{17,19,20}$

The conventional wide excision technique ${ }^{17}$ or complete excision or destruction of the cyst wall is the gold standard for treatment of EC because it can prevent recurrence. ${ }^{1}$ This technique involves dissection and complete removal of the cyst from surrounding tissue through elliptical incisions, ${ }^{17}$ approximately the same diameter as the cyst. ${ }^{20}$ There will be no recurrences if the entire cyst wall is removed. ${ }^{17}$ This timeconsuming endeavor ${ }^{4,17,19}$ frequently leads to significant scarring ${ }^{4,17,19,20}$ compared to minimal excision or punch biopsy. Minimal excision and punch excision techniques involve exposing the cyst contents through a 2 to $3 \mathrm{~mm}$ incision. Following expulsion of the cyst contents, the loosened capsule is delivered through a small opening of the incision. ${ }^{17}$ Closure with suture is optional. ${ }^{19}$ This technique offers a shorter procedural time, minimal bleeding, faster healing times, ${ }^{17}$ and less scarring for optimal cosmetic results, ${ }^{4}$ but has a slightly higher rate of recurrence. ${ }^{17}$ 
In this report, the ECs were treated by conventional wide excision technique for ECs on the back and minimal excision technique for the ECs on the chest and gluteal regions (Figure 3). The patient also received triamcinolone acetonide intralesional injection for the $\mathrm{EC}$ on the right temple. All procedures showed good results and the patient was satisfied. The conventional wide excision technique was considered to prevent recurrence as well as to obtain sample for histopathological examination. The minimal excision technique and triamcinolone acetonide intralesional injection were considered in order to provide optimal cosmetic results.

\section{Conclusions}

To conclude, EC should always be considered when diagnosing a skin-colored nodule even if the size and number are unusual. Appropriate clinical and histopathological findings of the skin-colored nodules are needed to establish the definite diagnosis of EC. Only scarce reports of generalized multiple ECs and giant EC have been reported, mainly in the form of generalized multiple ECs that occurred together with a giant EC. Here, we report a rare and unusual case, to best of our knowledge, of generalized multiple ECs with a giant $\mathrm{EC}$ on the left gluteal region of a male patient. In this report, the diagnosis of EC was established based on the clinical and histopathological findings, which are cysts containing keratin and lined by wall of stratified squamous epithelia. Conventional wide excision technique, minimal excision technique, and triamcinolone acetonide intralesional injection were the treatments of choice for this case.

\section{Abbreviations}

EC, epidermoid cyst.

\section{Acknowledgments}

Authors would like to thank all staff of the Dermatology and Venereology Department, Faculty of Medicine Universitas Padjadjaran - Hasan Sadikin General Hospital Bandung.

\section{Author Contributions}

All authors made a significant contribution to the work reported, whether that is in the conception, study design, execution, acquisition of data, analysis and interpretation, or in all these areas; took part in drafting, revising or critically reviewing the article; gave final approval of the version to be published; have agreed on the journal to which the article has been submitted; and agree to be accountable for all aspects of the work.

\section{Funding}

The authors declare that this study has received no financial support.

\section{Disclosure}

The authors report no conflicts of interest in this work.

\section{References}

1. Cuda JD, Rangwala S, Taube JM. Benign epithelial tumors, hamartomas, and hyperplasias. In: Kang S, Amagai M, Bruckner A, et al., editors. Fitzpatrick's Dermatology. 9th ed. New York: McGraw-Hill; 2019:1799-1819.

2. Stone MS, et al. Cysts. In: Bolognia J, Schaffer JV, Cerroni L, editors Dermatology, 4th. Missouri: Mosby Elsevier; 2018:1917-1930.

3. Lear JT, Madan V. Cutaneous cysts. In: Barker J, Bleiker T, Chalmers R, Creamer D, Griffiths C, editors. Rook's Textbook of dermatology. 9th ed. New Jersey: Wiley Blackwell; 2010:134.1-5.

4. Hoang VT, Trinh CT, Nguyen CH, et al. Overview of epidermoid cyst. Eur J Radiol. 2019;6:291-301. doi:10.1016/j.ejro.2019.08.003

5. Sabhnani G, Mohan NK, Reddy G, et al. Giant epidermal cyst of the gluteal region. Int Surg J. 2016;3:954-955. doi:10.18203/2349-2902. isj20161174

6. Sharma R, Padhy B. Giant epidermoid cyst: a rarity or negligence? Pan Afr Med J. 2018;20:237.

7. Nigam JS, Bharti JN, Nair V, et al. Epidermal cysts: a clinicopathological analysis with emphasis on unusual findings. Int J Trichology. 2017;9 (3):108-112. doi:10.4103/ijt.ijt_16_17

8. Polychrinidis A, Perente S, Botaitis S, et al. Giant multilocular epidermoid cyst on the left buttock. Dermatol Surg. 2005;31 (10):1323-1324. doi:10.1097/00042728-200510000-00011

9. Umemoto N, Toda S, Sugawara H, et al. Ruptured giant epidermal cyst on the buttock: report of a case and review of the literature. Skin Surg. 2002;11(1):7-9.

10. Tchernev G, Temelkova I, Yungareva I, et al. Multiple epidermal cysts of the scalp: dermatosurgical approach with favourable outcome! Open Access Maced J Med Sci. 2019;7(9):1509-1511. doi:10.3889/oamjms.2019.257

11. Won JH, Lee MJ, Park JS, et al. Multiple epidermal cysts in lowe syndrome. Ann Dermatol. 2010;22(4):444 446. doi:10.5021/ad.2010. 22.4.444

12. Yuksel ME, Tamer F. Multiple widespread epidermal cysts of the skin: an unusual presentation. Acta Dermatovenerol Alp Pannonica Adriat. 2016;25(2):23-24. doi:10.15570/actaapa.2016.6

13. Houdek MT, Warneke JA, Pollard CM, et al. Giant epidermal cyst of the gluteal region. Radiol. Case Rep. 2010;5(4):1-4. doi:10.2484/rcr.v5i4.476

14. Zouboulis CC, Katsambas AD, Kligman AM. Acne vulgaris. In: Zouboulis CC, editor. Pathogenesis and Treatment of Acne and Rosacea. 1st ed. New york: Springer; 2014:495-507.

15. Mayer JE, Miller MD, Biriea SA. Symmetric multilocular epidermoid cysts on the face: an unusual presentation of a common lesion. JAAD Case Rep. 2018;4(4):337-339. doi:10.1016/j.jdcr.2017.12.014

16. Weedon D. Cysts, Sinuses, and Pits. Dalam: Weedon's Skin Pathology. 3rd ed. Philadelphia: Elsevier; 2010:442-457.

17. Moore RB, Fagan EB, Hulkower S, et al. What's the best treatment for sebaceous cyst? J Fam Pract. 2007;4:315-316.

18. Jakhar D, Kaur I. Intralesional drainage injection of triamcinolone acetonide for epidermal cyst. J Am Acad Dermatol. 2017;78(6):e14950. doi:10.1016/j.jaad.2017.12.008

19. Zuber TJ. Minimal excision technique for epidermoid (sebaceous) cysts. Am Fam Physician. 2002;65(7):1409-1412.

20. Rao K, Tehrani H. Excision of epidermoid cyst with a minimal linear incision. Dermatol Online J. 2006;12(1):21. 


\section{Publish your work in this journal}

The International Medical Case Reports Journal is an international, peer-reviewed open-access journal publishing original case reports from all medical specialties. Previously unpublished medical posters are also accepted relating to any area of clinical or preclinical science. Submissions should not normally exceed 2,000 words or 4 published pages including figures, diagrams and references. The manuscript management system is completely online and includes a very quick and fair peer-review system, which is all easy to use. Visit http://www.dovepress.com/testimonials.php to read real quotes from published authors. 